\title{
EVALUATION OF CLINICAL PERIODONTAL CONDITIONS IN SMOKERS AND NON-SMOKERS
}

\author{
Lucinara Ignez Tavares LUZZI ${ }^{1}$, Sebastião Luiz Aguiar GREGHI ${ }^{2}$, Euloir PASSANEZI ${ }^{3}$, Adriana Campos Passanezi SANT’ANA ${ }^{4}$, \\ José Roberto Pereira LAURIS ${ }^{5}$, Tânia Mary CESTARI ${ }^{6}$
}

\author{
1- DDS, Graduate student, Department of Prosthodontics and Periodontics, Bauru School of Dentisty, São Paulo State University, Bauru, SP, \\ Brazil. \\ 2- DDs, PhD, Assistant Professor, Department of Prosthodontics and Periodontics, Bauru School of Dentisty, São Paulo State University, \\ Bauru, SP, Brazil. \\ 3- DDS, MSc, PhD, Chair Professor, Discipline of Periodontics, Department of Prosthodontics and Periodontics, Bauru School of Dentisty, São \\ Paulo State University, Bauru, SP, Brazil. \\ 4- DDS, MSc, PhD, Assistant Professor, Department of Prosthodontics and Periodontics, Bauru School of Dentisty, São Paulo State University, \\ Bauru, SP, Brazil. \\ 5- DDS, MSc, PhD, Assistant Professor, Department of Pediatric Dentistry, Orthodontics and Public Health, Bauru School of Dentisty, São \\ Paulo State University, Bauru, SP, Brazil. \\ 6- DDs, PhD Sudent, Department of Biological Sciences, Laboratory of Histology, Bauru School of Dentisty, São Paulo State University, \\ Bauru, SP, Brazil.
}

Corresponding address: Dra. Lucinara Ignez Tavares Luzzi - Rua 7 de setembro 2471, Centro, Cascavel, PR, Brazil, $85802-100$ Phone: +55-45-32251880/ +55-45-9973-7300 - e-mail: lucinara@brturbo.com.br

Received: September 11, 2006 - Modification: April 2, 2007 - Accepted: October 1, 2007

\begin{abstract}
G iven that tobacco smoking habit is a risk factor for periodontal diseases, the aim of this study was to compare clinical periodontal aspects between smokers and non-smokers. The clinical status were assessed in 55 patients, 29 smokers and 26 non-smokers, aged 30 to 50 years, with mean age of 40. The clinical parameters used were: probing depth (PD), plaque index (PI), gingival index (GI), clinical attachment level (CAL), gingival recession (GR) and gingival bleeding index (GBI) for arches (upper and lower ) and teeth (anterior and posterior). Tooth loss was also evaluated in both groups. Multiple regression analysis showed: tendency of greater probing depth and clinical attachment level means for smokers; greater amount of plaque in smokers in all regions; greater gingival index means for non-smokers with clinical significance $(p<0.05)$ in all regions. Although, without statistical significance, the analysis showed greater gingival bleeding index means almost always for nonsmokers; similar gingival recession means in both groups and tendency of upper tooth loss in smokers and lower tooth loss in non-smokers. The findings of this study showed that clinical periodontal parameters may be different in smokers when compared to non-smokers and that masking of some periodontal signs can be a result of nicotine's vasoconstrictor effect.
\end{abstract}

Uniterms: Smoking; Periodontal disease; Periodontal parameters.

\section{INTRODUCTION}

Nowadays, it is absolutely accepted that tobaccoism is a serious public health problem. In addition to the known harmful effects caused to the human body, the oral cavity is directly affected by the smoking habit. Several studies have demonstrated that tobacco is, per se, a risk factor in the etiology of periodontal disease, with a local and systemic effect ${ }^{9,28}$

A positive association between cigarette smoking and acute necrotizing ulcerative gingivitis (ANUG) was first reported over 4 decades ago $^{23}$. Recent studies have confirmed a greater prevalence of attachment $\operatorname{loss}^{2,25}$, recession ${ }^{2}$, severe destructive periodontal disease ${ }^{9,12}$ and less favorable response to nonsurgical ${ }^{2,25}$ or surgical ${ }^{2}$ periodontal treatment in smokers, as compared to nonsmokers. Additionally, it seems difficult to discern the effect caused by tobacco from that provoked by bacterial infection ${ }^{15}$. In this regard, recent knowledge on plaque formation is controversial as for the possibility that smoking may interfere with the natural occurrence of plaque accumulation on dental surfaces.

Regarding periodontal blood supply, several studies related to plaque-induced gingivitis, showed a reduction of clinical signs ${ }^{10,11}$, with a smaller propensity for gingival bleeding ${ }^{7,8,10}$, owing to vascular changes caused by smoking ${ }^{7}$.

Clinical and epidemiological studies also reported that most refractory periodontal condition cases occur in smokers and that there is a dose-dependant relation, in which, the 
greater the quantity of cigarettes smoked a day and the duration of the smoking habit, the greater the periodontal bone loss ${ }^{9}$.

Therefore, the purpose of this study was to compare periodontal clinical parameters of probing depth (PD), clinical attachment level (CAL), gingival index (GI),gingival bleeding index (GBI), plaque index (PI) and gingival recession (GR) between smoking and non-smoking groups and correlate these parameters between groups.

\section{MATERIALAND METHODS}

The sample was composed of 55 subjects, being 29 smokers (55.2\% females and $44.8 \%$ males) and 26 nonsmokers (65.4\% females and 34.6\% males). The participants were recruited from private practices in the city of Cascavel, PR, Brazil. The patients attended a lecture on periodontal disease, tobacco as a risk factor on the oral cavity and were given information on the research project. The study design and informed consent form were approved by the Ethics in Research Committee of the Dental School of Bauru, University of São Paulo (Process number 019/2002/FOB).

The criteria for sample screening were: 1 ) non-smokers and smokers between 30 and 50 years of age; 2) smokers of approximately 1 pack or more of cigarettes/day; 3) absence of systemic or acute periodontal alterations; 4) no periodontal treatment in the previous 6 months; 5) no antibiotic therapy within the previous 8 months; 6 ) at least one region with periodontal pocket of $5 \mathrm{~mm}$ or more, in a posterior tooth.

Patients were given no instruction on hygiene and oral physiotherapy, and no procedure of basic preparation was carried out, not to interfere with clinical data collection.

The following clinical parameters were evaluated: Probing depth (PD), clinical attachment level (CAL), gingival Index (GI-Lö $\left.{ }^{19}\right)$, gingival bleeding index (GBI-Ainamo and $\mathrm{Bay}^{3}$ ), plaque index (PI-Silness and Löe ${ }^{27}$ ) and gingival recession (GR).

The measurements were performed with a Michigan ( $\mathrm{Hu}-$

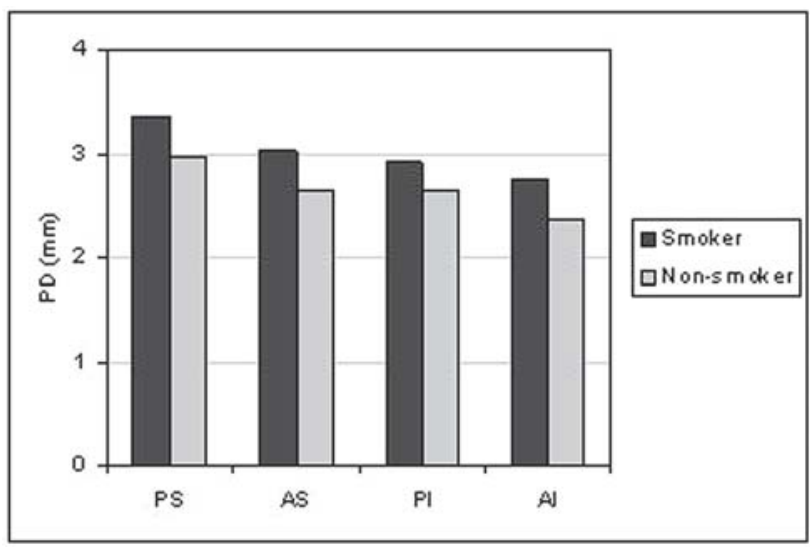

FIGURE 1- Graph of the probing depth (PD) by regions (PS= postero-superior; $\mathrm{AS}=$ antero-superior; $\mathrm{PI}=$ postero-inferior; $A I=$ antero-inferior) between smokers $(n=29)$ and nonsmokers $(n=26)$
Friedy PC15 USA) millimeter manual periodontal probe, in six sites of each tooth (distobuccal surface, center of vestibular surface, mesiobuccal surface, distolingual surface, center of lingual surface and mesiolingual surface). In order to minimize the variability of the examination, during assessment of $\mathrm{PI}^{27}$, mesial (M) and distal (D) measurements were made only in the buccal surface because the palatal/ lingual surfaces were indirectly seen with a buccal mirror, according to the technique proposed by Silness and Löe ${ }^{27}$.

All clinical periodontal parameters (PD, CAL, GI, GBI, PI and GR) were analyzed statistically by regions (PS = posterosuperior; $\mathrm{AS}$ = antero-superior; $\mathrm{PI}=$ postero-inferior; $\mathrm{AI}=$ antero-inferior).

Multiple regression analysis was performed for comparison between smokers $(n=26)$ and non-smokers $(n=29)$, using age and gender as the control variables and adopting a 5\% significance level. A sample size of 26 patients is capable of proving a difference of 1.7 times the standard deviation, for a significance level of $5 \%$ and a statistical power of $80 \%$.Calculations were performed using the SPSS statistical software version 13.0 (SPSS Inc, Chicago, IL, USA).

\section{RESULTS}

For all situations evaluated, there was a trend towards greater PD (Figure 1) and CAL (Figure 2) means for the smoking group. GI means (Figure 3 ) were greater in the nonsmoking group, with statistical significance in all regions $(p<0.05)$. Although there were no statistically significant differences between smoking and non-smoking groups, there was an overall trend towards greater GBI means, almost always, for non-smokers (Figure 4). Regarding PI means between smokers and non-smokers (Figure 5), greater plaque accumulation was observed for the smoking group. In relation to GR, there was no constancy of greater values for smokers or non-smokers and, in none of the situations there were statistically significant differences (Figure 6).

Comparing the group of smokers, as for the number of missing teeth (Table 1), taking into account posterior/anterior

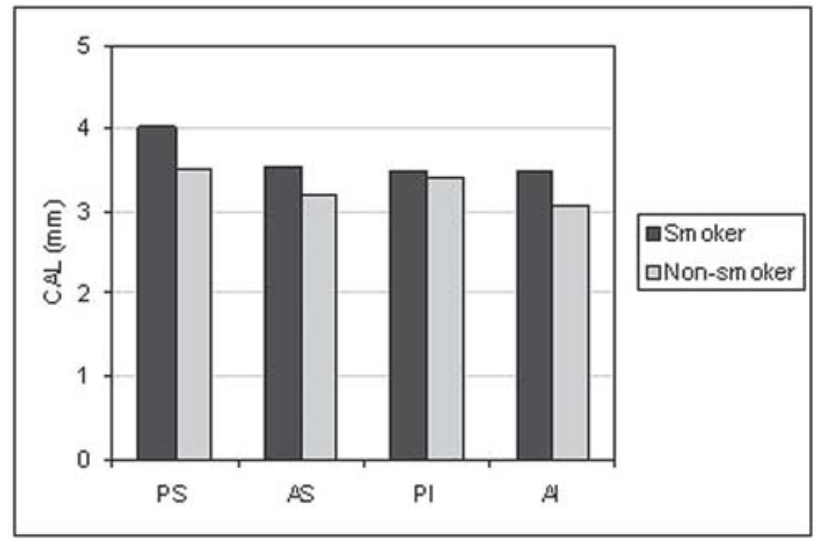

FIGURE 2- Graph of the clinical attachment level (CAL) by regions $(\mathrm{PS}=$ postero-superior; $\mathrm{AS}=$ antero-superior; $\mathrm{PI}=$ postero-inferior; $\mathrm{Al}=$ antero-inferior) between smokers $(n=29)$ and non-smokers $(n=26)$ 


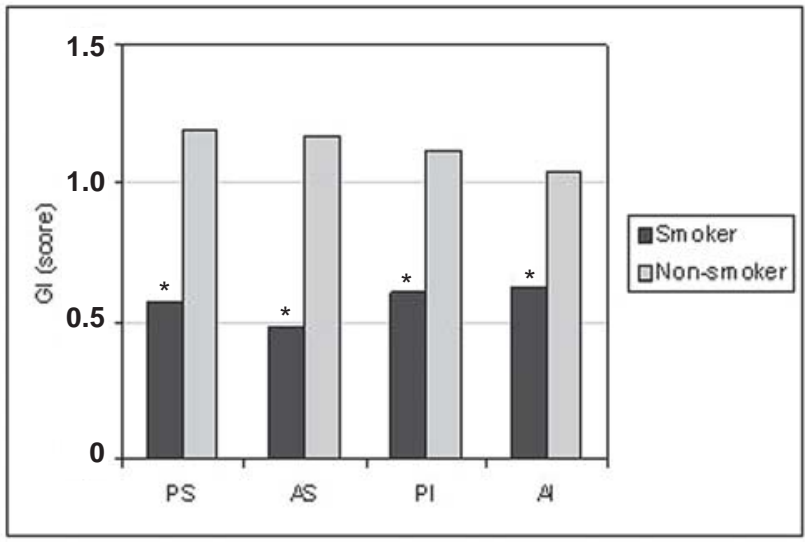

FIGURE 3- Graph of the gingival index (GI) by regions (PS= postero-superior; $\mathrm{AS}=$ antero-superior; $\mathrm{PI}=$ postero-inferior; $A I=$ antero-inferior) between smokers $(n=29)$ and nonsmokers $(\mathrm{n}=26)$

* Statistically significant difference $(P<0.05)$ between smokers and non-smokers.

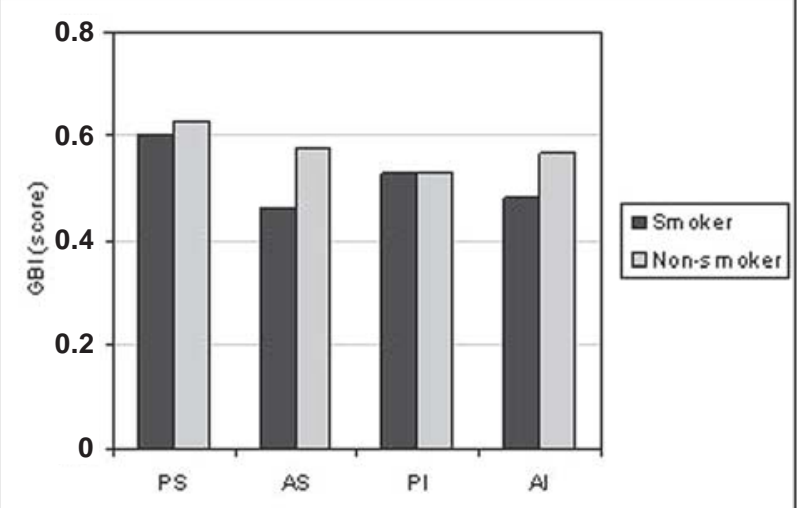

FIGURE 4- Graph of the gingival bleeding index (GBI) by regions (PS= postero-superior; $\mathrm{AS}=$ antero-superior; $\mathrm{PI}=$ postero-inferior; $\mathrm{Al}=$ antero-inferior) between smokers $(n=29)$ and non-smokers $(n=26)$

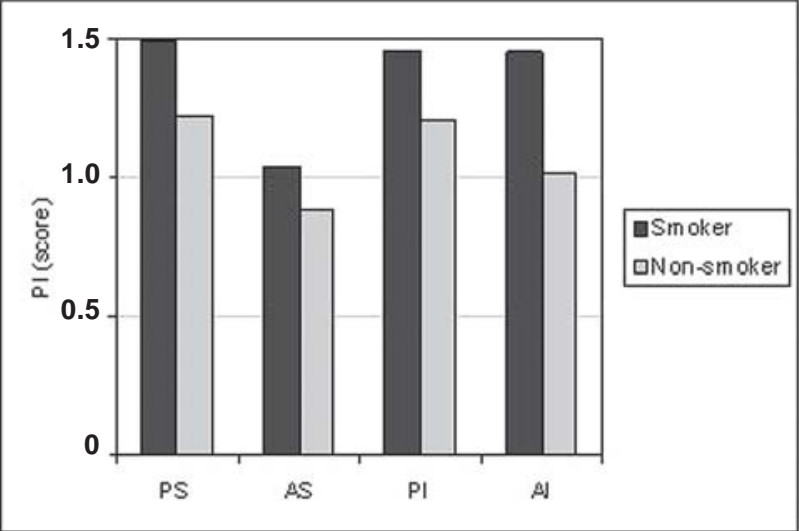

FIGURE 5- Graph of the plaque index $(\mathrm{PI})$ by regions (PS= postero-superior; $\mathrm{AS}=$ antero-superior; $\mathrm{PI}=$ postero-inferior; $A I=$ antero-inferior) between smokers $(n=29)$ and nonsmokers $(n=26)$

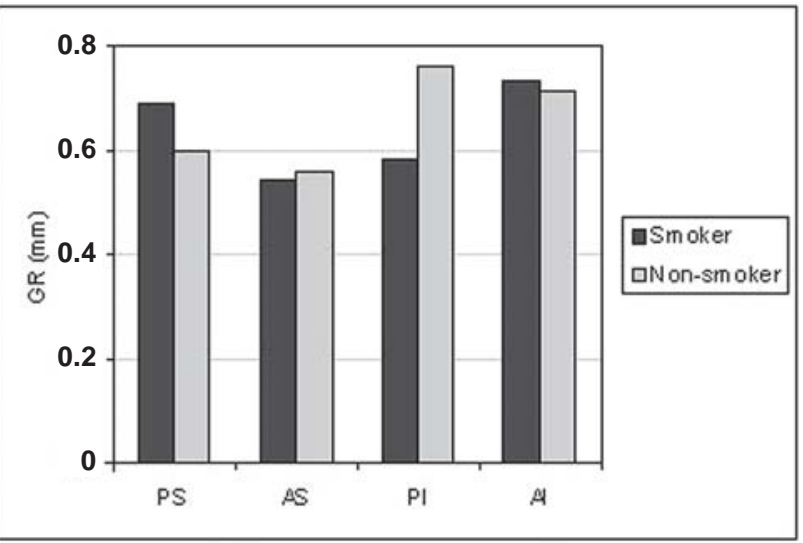

FIGURE 6- Graph of the gingival recession (GR) by regions (PS= postero-superior; $\mathrm{AS}=$ antero-superior; $\mathrm{PI}=$ posteroinferior; $\mathrm{Al}=$ antero-inferior) between smokers $(\mathrm{n}=29)$ and non-smokers $(n=26)$

TABLE 1- Comparative Multiple Regression Analysis of variables between smokers $(n=29)$ and non-smokers $(n=26)$

\begin{tabular}{lll} 
Variable & Smoker & Non-smoker \\
\hline Age (years) & $40.2( \pm 6.6)$ & $40.8( \pm 6.1)$ \\
No cigaretts/day & $24.5( \pm 15.2)$ & \\
Gender & $55.2 \% \mathrm{~F}$ & $65.4 \% \mathrm{~F}$ \\
& $44.8 \% \mathrm{M}$ & $34.6 \% \mathrm{M}$ \\
\hline
\end{tabular}

TABLE 2- Comparative Multiple Regression Analysis of the number of missing teeth per area (anterior and posterior) and arch (upper and lower) for the groups of smokers $(n=29)$ and non-smokers $(n=26)$

\begin{tabular}{lllll}
\hline & \multicolumn{2}{c}{ Smoker } & \multicolumn{2}{c}{ Non-smoker } \\
Regions & $\overline{\mathbf{x}}$ & SD & $\overline{\mathbf{x}}$ & SD \\
\hline PS & 3.55 & 2.11 & 3.15 & 1.99 \\
AS & 0.75 & 1.35 & 0.65 & 1.26 \\
PI & 4.06 & 1.98 & 4.19 & 2.02 \\
Al & 0 & 0 & 0.19 & 0.63 \\
\hline
\end{tabular}

$p<0.05^{\star}$ : statistically significant.

and superior/inferior regions, the differences were not significant statistically, though there was a tendency for greater upper tooth loss in smokers and greater lower tooth loss in non-smokers.

Regarding the variables analyzed between the groups of smokers and non-smokers, Table 2 shows a mean age of 40 years old, a greater participation of females and a mean of 24.5 cigarettes smoked a day. 


\section{DISCUSSION}

In addition to bacterial plaque, other factors can modify the host response, predisposing the individual to a higher risk of periodontal disease. Among the factors considered as fundamental in the host resistance-bacterial aggression interrelation, hereditary predisposition, age, systemic conditions, stress, drugs and tobacco may be cited.

Nowadays, it is known that the action of tobacco in the periodontium might predispose the individual to various periodontal diseases ${ }^{7,11,13,14,16}$ and not only to $\mathrm{ANUG}^{23}$. Several studies have highlighted aspects of tobacco relation with plaque accumulation ${ }^{6,10,11,21,26}$, inflammation ${ }^{11,17,21,26}$, calculus $^{2,9,23}$, immune response $\mathrm{i}^{11,13}$, toxicity ${ }^{14,22}$ and plaque microbiology ${ }^{14,16,28}$, among others. However, the large number of studies in this field is justified by the fact that the effects of cigarette smoking on the periodontal status have not been completely elucidated. Thus, the present study aimed at investigating some aspects of this interrelation.

The age range of the study subjects was delimited in order to exclude those either too young or too old. This approach was important for the sample as an effort to minimize aspects related to overage, which might influence the periodontal conditions. On the other hand, the effects of smoking (time of action) might be less expressive in younger individuals, so they were also excluded, establishing a mean age of 40 years old (Table 2).

Studies with large sample sizes are found in the literature. However, in many of them, the examinations are carried out by different professionals and data are obtained only from some sites of the mouth, such as the use of CPITN ${ }^{4,12}$. It is noteworthy that all records of the study were accomplished by a single examiner, previously calibrated by the Kappa test, which is important for an accurate standardization, especially in the examinations where the subjectivity load is critical. The intraexaminer agreement was strong (0.90).

The results of the present study, in which clinical parameters were considered, showed an evident negative influence of tobacco, particularly for PD (Figure 1) and CAL (Figure 2). There was a tendency of greater PD and CAL means in all regions analyzed in smokers, in relation to nonsmokers.

The results of this study are consistent with those of previous studies ${ }^{12,13,18,28}$. It should be highlighted that, in a previous study ${ }^{2}$, the prevalence of greater PDs occurred for smokers of cigarettes, cigars or pipe, alike.

Stoltenberg, et al. ${ }^{28}$ (1993) found 5 times more periodontal pockets $=3.5 \mathrm{~mm}$ in smokers, in the proximal surfaces of all upper teeth, with no qualitative differences in the microbiota of smokers and non-smokers.

Less favorable PD responses in smokers are observed after periodontal therapies ${ }^{1,24,25}$. A smaller PD reduction in all regions after nonsurgical periodontal therapy and a greater difference for the antero-superior region was observed by Preber and Bergström ${ }^{24}$ (1985). As for maintenance therapy, Jansson and Hagström ${ }^{15}$ (2002), found greater PD in subjects who interrupted the treatment, independently of the smoking habit. When the tobacco variable was considered, the authors demonstrated that smokers with no periodontal support therapy had higher risk of periodontitis progression.

Current studies also associate smokers with greater periodontal attachment loss $2,4,14,18$. The results obtained by Haffajee and Socransky ${ }^{14}$ (2001) were similar to those of this study. The authors examined the clinical characteristics of periodontal disease and standards of insertion loss among usual smokers, occasional smokers and those who had never smoked, in 6 sites per tooth, in all teeth, excluding the third molars. The study showed that this parameter was more significant in usual smokers than in the other 2 groups, particularly, in the palatal upper sites and in antero-inferior teeth. According to the authors, these greater attachment losses observed in these sites suggested the possibility of a local effect of cigarette.

In the present investigation, the dose-reaction relation may have influenced the results of this variable as well because the study subjects smoked 24.5 cigarettes/day on the average (Table 2). In this context, Martinez-Canut, et al. ${ }^{20}$ (1995) also related the cigarette dose-reaction to CAL, showing a direct relation of greater insertion loss with the increase in the number of cigarettes consumed.

Although it was not within the scope of this study, another less favorable parameter in smokers is the insertion gain, following periodontal therapy. Ah, et al. ${ }^{1}$ (1994) evaluated the effect of tobacco on clinical response to surgical and non-surgical periodontal therapy between smokers and non-smokers. The analysis demonstrated that smokers had a significantly smaller CAL gain.

Gingival bleeding is considered an objective sign also associated with gingivitis and periodontitis. There are some evidences that tobacco may be associated with less expressive signs and symptoms in periodontal inflammation, such as gingival bleeding, erythema and edema, indicating a suppressive influence in inflammatory response , $8,10,11,13,17^{\text {. }}$

In this study, the comparative analysis of GI (Figure 3), between smokers and non-smokers, with a mean age of 40 years, showed that in all analyzed situations, there were greater values for non-smokers, which reflects a greater clinical inflammatory exuberance, in this group. These greater means in non-smokers may be related to the nicotine's vasoconstrictor effect. Several articles are consistent with this work, revealing that the clinical signs of inflammation are less evident in smokers ${ }^{7,11,14,17,21}$. Other researches reported that the dose-dependent reaction would attenuate the clinical signs, proportionally to tobacco consumption $^{20}$. On the other hand, some works did not demonstrate a relation with the gingival conditions, in subjects with gingival health ${ }^{6}$ or presented with periodontal disease ${ }^{7}$.

The divergences in relation to gingival conditions are stated in various articles. Some more ancient works, correlated the GI, not considering the oral hygiene standards, showing a greater inflammation evidence in smokers ${ }^{21,23,26}$. In this context, Baab, et al. ${ }^{5}(1987)$ presented the effects of cigarette on blood flow, causing a significant increase and not a decrease in gingival blood circulation, concluding that 
the theory that smoking would damage the gingival blood flow might not be true in smokers. However, this result might be related to the reduced age of the subjects participating in the experiment (19 to 25 years old).

As for GBI (Figure 4), although no statistically significant differences were found, there was a general trend to more bleeding sites in the non-smoker group, and, as observed for the GI, the clinical aspects seem to be masked by tobacco.

Goultschin, et al. ${ }^{12}$ (1990) compared individuals with mean age similar to that of the population of this study, showing that smokers had smaller GBI means than non-smokers. The authors attributed this finding to a reduction in the gingival flow, caused by nicotine.

Another essential aspect in this clinical analysis is the bacterial plaque accumulation (Figure 5). It is important to highlight that the study subjects were given no instruction on oral hygiene along the research, not to bias data collection. However, in all analyzed situations, there was a general trend for greater PI means for smokers. When comparing PI and GI in smokers, no inflammatory characteristics were observed, proportionally to the amount of plaque accumulation. This fact may be related to nicotine's vasoconstrictor effect, causing a decrease in the blood flow and masking the local inflammation.

There are controversies in relation to plaque accumulation in smokers. The findings of this study are in agreement with those of $\mathrm{Ah}^{1}$, while other authors have found similar plaque scores ${ }^{4,7,10,11,17,28}$, a hypothesis that smokers may be less motivated to keep a high-quality oral hygiene ${ }^{6,10}$ or did not show a significant difference in plaque accumulation ${ }^{8,9,18,21,26}$ when the groups were matched by oral hygiene. Other studies ${ }^{9,18}$ showed that there was no significant difference in the PI means, for smoking and nonsmoking individuals, with the same oral hygiene level. Bergström, et al. ${ }^{9}$ (1991) suggested a direct influence of tobacco on periodontal health, independently of plaque infection.

It is noteworthy that the qualitative difference in bacterial plaque has also been addressed in the present study. Some authors do not show this association ${ }^{13,16,17}$, while others confirm the difference in microbiological quality ${ }^{6,22}$. This difference in the prevalence of anaerobic species would also explain the greater periodontal destruction severity in smokers than in non-smokers ${ }^{14}$.

While assessing gingival recessions between smokers and non-smokers (Figure 6), it was not possible to detect significant differences for any of the analyses. In addition, there was not a constant tendency for the groups. Evidently, it cannot be stated categorically, based on the results of the present study, that tobaccoism does not interfere with gingival recession; however, the multiple factors involved in the etiology of gingival recessions, which were not addressed in this study, should be considered. In this regard, Albandar, et al. ${ }^{2}$ (2000) found greater prevalence of recessions, with $=3 \mathrm{~mm}$ gingival, in smokers of cigarette, pipe and cigars, as compared to non-smokers.

Another goal of this study was to compare the number of missing teeth by area (anterior and posterior) and arch (upper and lower) in the smoking and non-smoking groups (Table 1). In this aspect, it was not possible to establish a significant condition for any of the situations. Nevertheless, there was a tendency for a greater upper tooth loss in smokers and a greater lower tooth loss in non-smokers.

A previous epidemiological study ${ }^{4}$ examined the periodontal condition and the smoking habits of 1,093 individuals in the 35-75-year-old age range, concluding that smoking is a significant risk factor for dental loss. The same condition has reported in relation to types of tobacco by Albandar, et al. ${ }^{2}$ (2000), who suggested that smokers of cigarette, cigar or pipe present a greater prevalence of periodontal problems and greater dental loss than nonsmokers.

All aspects discussed hereby are of paramount importance in the prevalence of tobacco as a periodontal risk factor. In general, the most related issues to the scope of this study were addressed. Various other subjects must be considered and further research should be carried out in order to elucidate the divergences existing on the interrelation tobacco-periodontal disease.

\section{CONCLUSIONS}

Based on the methodology employed and considering its limitations, it may be concluded that: 1 . Tobaccoism may aggravate the probing depth (PD), the clinical attachment level (CAL) and the plaque index (PI); 2 . The gingival indexes (GI) and gingival bleeding (GBI) might suffer interference from tobaccoism and be masked; 3. Gingival recessions (GR) alone are not clearly associated with tobaccoism; 4. In smokers, there was a trend to greater dental loss means in the upper arch.

\section{REFERENCES}

1- Ah MKB, Johnson GK, Kaldahl WB, Patil KD, Kalkware KL. The effect of smoking on the response to periodontal therapy. J Clin Periodont. 1994;21:91-7.

2- Albandar JM, Streckfus CF, Adesanya MR, Winn DM. Cigar, pipe, and cigarette smoking as risk factors for periodontal disease and tooth loss. J Periodont. 2000;71:1874-881.

3- Ainamo J, Bay I. Problems and proposals for recording gingivitis and plaque. Int Dent J. 1975;25:229.

4- Axelsson P, Paulander J, Lindhe J. Relationship between smoking and dental status in 35, 50, 65 and 75 years old individuals. J Clin Periodont. 1998;25:297-305.

5- Baab DA, Ôberg PA. The effect of cigarette smoking on gingival blood flow in humans. J Clin Periodont. 1987;14:418-24.

6- Bastiann RJ, Waite IM. Effects of tobacco smoking on plaque development and gingivitis. J Periodontol. 1978;49:480-2.

7- Bergström J. Oral hygiene compliance and gingivitis expression in cigarette smokers. Scand J Dent Res. 1990;98:497-503.

8- Bergström J, Eliasson S, Dock J. Exposure to tobacco smoking and periodontal health. J Clin Periodontol. 2000;27:61-8. 
9- Bergström J, Eliasson S, Preber H. Cigarette smoking and periodontal bone loss. J Periodontol .1991;62:242-6.

10- Bergström J, Eliasson S, Preber H. Influence of cigarette smoking on vascular reaction during experimental gingivitis. Scand J Dent Res. 1988;96(1):34-9.

11- Bergström J, Preber H. The influence of cigarette smoking on the development of experimental gingivitis. J Periodontal Res.1986;21:668-76.

12- Goultschin J, Cohen HDS, Donchin M, Brayer L, Soskolne WA. Association of smoking with periodontal treatment needs. J Periodontol.1990;61:364-7.

13- Haffajee AD, Socransky, S. Socransky SS. Relationship of cigarette smoking to the subgingival microbiota. J Clin Periodontol. 2001;28:377-88.

14- Haffajee AD, Socransky SS. Relationship of cigarette smoking to attachment level profiles. J Clin Periodontol. 2001;28:283-95.

15- Jansson LE, Hagström KE. Relationship between compliance and periodontal treatment outcome in smokers. J Periodontol. 2002;73(6):602-7.

16- Kamma JJ, Nakou M, Baehni PC. Clinical and microbiological characteristics of smokers with early onset periodontitis. J Periodont Res. 1999;34:25-33.

17- Lie MA, Van der Weijden GA, Timmerman MF, Loss BG, Van der Steenbergen TJM, Van der Velden U. Oral microbiota in smokers and non-smokers in natural and experimentally-induced gingivitis. J Clin Periodontol. 1998;25:677-86.

18- Linden GJ, Mullally BH. Cigarette Smoking and periodontal destruction in young adults. J Periodontol. 1994;65:718-23.

19- Löe H. The gingival index, the plaque index and the retention index systems. J Periodontol .1967;36:610.

20- Martinez-Canut P, Lorca A, Magan R. Smoking and periodontal disease severity. J Clin Periodontol.1995;22:743-9.

21- Modeer T, Lavstedt S, Ahlund C. Relation between tobacco consumption and oral Health in Swedish schoolchildren. Acta Odontol Scand.1980;38:223.

22- Pabst MJ, Pabst KM, Collier JA, Coleman TC, Lemons-Prince ML, Godat MS, et al. Inhibition of neutrophil and monocyte defensive functions by nicotine. J Periodontol.1995;66(12):1047-55.

23- Pindborg JJ. Tobacco and gingivitis. II. Correlation between consumption of tobacco, ulceromembranous gingivitis and calculus. J Dent Res. 1949t; 28(5):460-3.

24- Preber H, Bergströn J. The effect of non-surgical treatment on periodontal pockets in smokers and non-smokers. J Clin Periodontol. 1985;13: 319-23.
25- Renvert S, Dahlén G, Wikströn $M$. The clinical and microbiological effects of non-surgical periodontal therapy in smokers and non-smokers. J Clin Periodontol. 1998;25:153-7.

26- Sheiham A. Periodontal disease and oral cleanliness in tobacco smokers. J Periodontol. 1971;42(5): 259-63.

27- Silness J, Löe H. Periodontal disease in pregnancy. Acta Odont Scand. 1964;22:121-35.

28- Stoltenberg JL, Osborn JB, Pihlstrom BL, Hertzberg MC, Aeppli DM, Wolff LF, Fischer GE. Association between cigarette smoking, bacterial pathogens, and periodontal status. J Periodontol. 1993;64:1225-30. 